\title{
Research Paper: Evaluation of Subclinical Hypothyroidism on Auditory Divided Attention
}

\author{
Fatemeh Khorasani $^{1}$ (D), Nematollah Rouhbakhsh ${ }^{1 *}$ (D), Ahmad Geshani ${ }^{1}$, Mohammad Reza Mohajeri Tehrani ${ }^{2}$, Mostafa Qorbani $^{3}$
}

1. Department of Audiology, School of Rehabilitation, Tehran University of Medical Sciences, Tehran, Iran.

2. Endocrinology and Metabolism Research Institute, Tehran University of Medical Sciences, Tehran, Iran.

3. Non-communicable Diseases Research Center, Alborz University of Medical Sciences, Karaj, Iran.

\begin{tabular}{|c|c|}
\hline $\begin{array}{l}\text { Use your device to scan } \\
\text { and read the article online }\end{array}$ & \\
\hline 口田田 & ditation: Khorasani F, Rouhbakhsh N, Geshani A, Mohajeri Tehrani MR, Qorbani M. Evaluation of Subclinical Hypothyroidism \\
\hline 7topto & on Auditory Divided Attention. Journal of Modern Rehabilitation. 2019; 13(1):39-48. http://dx.doi.org/10.32598/JMR.13.1.39 \\
\hline$x^{4}+4$ & d ol http://dx.doi.org/10.32598/JMR.13.1.39 \\
\hline
\end{tabular}

\section{(i) (8)}

Article info:

Received: 03 Jul 2018

Accepted: 25 Oct 2018

Available Online: 01 Jan 2019

\section{Keywords:}

Cognition, Attention, Adults, Hypothyroidism, Dichotic Listening tests

\section{A B S T RACT}

Introduction: Subclinical hypothyroidism is an endocrine disorder that can adversely affect cognitive performance. In this regard, patients with subclinical hypothyroidism may develop poor attention. However, the effects of this endocrine disorder on auditory attention is unclear. This study aims to evaluate the impact of subclinical hypothyroidism on auditory divided attention.

Materials and Methods: This cross-sectional, case control study was performed on 30 adult patients, aged 20-40 years, who met the study inclusion criteria. Based on their Thyroid Stimulating Hormone (TSH) level, the subjects were divided into two case groups (each with 15 patients) with a TSH level of $5<\mathrm{TSH} \leq 10$ and $10<\mathrm{TSH} \leq 15$. A healthy control group was recruited with matched age, sex, and education with the case groups. The participants were evaluated by the Persian version of the Bergen dichotic listening test. Among different experimental situations that included non-forced attention, forced right, and forced left, we chose the non-forced attention. Statistical analysis was done in SPSS V. 25.

Results: There was a significant difference between the subclinical hypothyroid $(5<\mathrm{TSH} \leq 10$ group) and controls in the scores of the right and left ear. However, there was no significant difference between scores of right and left ear in subclinical hypothyroid ( $10<\mathrm{TSH} \leq 15$ group). No significant difference in scores of the right and left ear was found between men and women in three groups.

Conclusion: Subclinical hypothyroidism had no effect on auditory divided attention.

* Corresponding Author:

Nematollah Rouhbakhsh, PhD.

Address: Department of Audiology, School of Rehabilitation, Tehran University of Medical Sciences, Tehran, Iran.

Tel: +98 (21) 77530636

E-mail: rohbakhn@tums.ac.ir 


\section{Introduction}

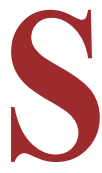

ubclinical hypothyroidism is a common endocrine disorder that occurs when Thyroid Stimulating Hormone (TSH) levels are higher than normal range $(0.27 \leq \mathrm{TSH} \leq 5 \mu \mathrm{IU} / \mathrm{mL})$ while the level of T3 (0.92-2.33 nmol/L) and T4 (5.13-14.1 $\mu \mathrm{g} / \mathrm{dL})$ hormones are within the normal range. However, in overt hypothyroidism, the levels of T3 and T4 hormones drop lower than normal $[1,2]$. The prevalence of subclinical hypothyroidism is more than overt hypothyroidism, and it is more common in women $[3,4]$.

Different studies show that subclinical hypothyroidism adversely affects cognitive performance, causing memory impairment, low concentration, and poor attention [5-7]. Mcdermot et al. found that people with subclinical hypothyroidism showed poor memory and reasoning [3]. Akintola et al. reported that in adults subclinical hypothyroidism like overt hypothyroidism manifested with deficits in cognitive abilities like memory, attention, and concentration [8].

Attention is one of the cognitive functions that has an essential role in information processing [9]. It is the ability to filter the information to obtain the preferred data [10]. Attention can advocate visual, auditory, and tactile information [11]. Auditory attention is the ability to focus on preferred acoustic stimuli while simultaneously receiving other stimuli. Because acoustic and phonetic features of the language are affected by auditory attention, it may have essential roles in reading and writing [12].

Auditory attention has various types, including divided attention and selective attention. The divided attention refers to simultaneously focusing on two or more acoustic stimuli present in dichotic situation. Selective attention refers to focus selectively on preferred information while ignoring other competitive stimuli [10]. Compared to selective attention, divided attention is a more difficult task and demands more brain activity because of focusing on two or more stimuli at the same time [13].

For this reason, any possible processing disorder can affect divided attention. Divided attention is a practical and challenging skill needed in everyday life activities such as listening to the teacher and taking notes simultaneously or listening to music, and somebody's talking at the same time [14].

The dichotic listening test is one of the most valid behavioral tests that are used for evaluating the function of the brain hemispheres, transferring information between two hemispheres, and diagnosis of central auditory disorders [13]. Bergen dichotic listening test is a dichotic test that is used widely to investigate auditory attention and language laterality in healthy people, individuals with brain injury, and patients with attention deficits [15]. In dichotic listening, two different stimuli are presented to the right and left ear simultaneously. In this experiment utilizing speech stimuli, the right ear usually obtains higher scores than the left ear in healthy people. This result shows that left hemisphere is specialized for language understanding $[16,17]$.

Various studies have evaluated the effects of subclinical hypothyroidism on different kinds of attention, but their results are controversial [18-21]. Some studies reported that subclinical hypothyroidism had a negative impact on auditory attention. For example, Paladugo et al. compared cognitive functions between patients with subclinical hypothyroid and control groups using latencies of P300 auditory evoked potentials. They found that subclinical hypothyroid patients had P300 latency prolongation compared with the control group [7].

Quijano et al. assessed auditory attention with the Reaction Time Test (RT) in subclinical hypothyroid patients. Their results showed slowed reaction time in subclinical hypothyroid patients [22]. Nystrom et al. also noted a decrease in auditory and visual attention performance in elderly patients with subclinical hypothyroidism [23]. Baldini et al. evaluated neuropsychological functions in subclinical hypothyroid patients. They assessed auditory attention with RT. Their findings showed that RT was not prolonged in subclinical patients. Thus subclinical hypothyroidism had no effect on auditory attention [18].

Gussekloo et al. evaluated the impact of subclinical hypothyroidism on attention with Stroop test. They reported that attention did not affect patients with subclinical hypothyroid [19]. Park et al. used digit span test to evaluate attention in patients with subclinical hypothyroid. They demonstrated that subclinical hypothyroid had no adverse effect on auditory attention in general [24]. Jorde et al. also used digit span test to evaluate the impact of subclinical hypothyroidism on attention. Their results did not show any changes in sustained attention or attention in general [25].

It is well known that thyroid and its disorders such as overt hypothyroidism have a detrimental effect on central nervous system, but the impact of subclinical hypothyroidism on cognitive functions is inconclusive and needs to be determined [26, 27]. Furthermore, most 
of the previous studies have been conducted on older population (because hypothyroidism is more prevalent in this group) or have considered a wide range of age in their sample [18, 28, 29]. Also previous studies did not use dichotic tests for the evaluation of auditory attention. For these reasons, in the present study, we evaluated the effects of subclinical hypothyroidism on auditory divided attention among young patients with subclinical hypothyroid by the Persian version of the Bergen dichotic listening test.

\section{Materials and Methods}

This cross-sectional case control study was conducted on two groups of patients with subclinical hypothyroidism, and one group of healthy participants (age range: 20-40 years) with each group consisted of 15 participants. The first subclinical hypothyroid $(5<\mathrm{TSH} \leq 10 \mu \mathrm{IU} / \mathrm{mL})$ group included nine women and six men, and the second subclinical hypothyroid $(10<\mathrm{TSH} \leq 15)$ group included 10 women and 5 men. This study was conducted in Audiology Clinic of Tehran University of Medical Sciences (TUMS).

The study participants were recruited from patients referring to Endocrine Clinic of Shariati Hospital affiliated to TUMS, and their diseases was approved by an endocrinologist. Their thyroid hormones levels were determined by blood tests. Four individuals in the first subclinical hypothyroid group and one individual in the second subclinical hypothyroid group had anti-thyroid peroxidase antibody (Anti-TPO Ab) higher than average, proving they had Hashimoto's thyroiditis, a kind of autoimmune disease.

The participants in three groups lacked any significant neurological and cognitive problems, did not use psychological drugs, alcohol or tobacco smoking, lacked history of head trauma, brain surgery and epilepsy audiological or neurological problems, had hearing threshold equal to or below $25 \mathrm{~dB}$ HL at octave frequencies from 250 to $8000 \mathrm{~Hz}$ and scored above $90 \%$ in speech discrimination score, had acoustic reflex at $0.5,1$, and $2 \mathrm{kHz}$ and type A tympanometry in both ears.

They were right-handedness following the standard of Edinburgh. They were monolinguals (speaking Persian) and had no musical experience. They were not under treatment for hypothyroidism before the tests. Their thyroid test results were the $5<\mathrm{TSH} \leq 10,10<\mathrm{TSH} \leq 15$, in the case (subclinical hypothyroid) groups, and $0.27 \leq \mathrm{TSH} \leq 5 \mu \mathrm{IU} / \mathrm{mL}$ in the control group.

The absence of any of the above criteria resulted in the exclusion of the subjects from the study. To recruit the partici- pants, we carried several evaluations to observe the study inclusion criteria. To roll out any severe cognitive involvement, depression, and anxiety, mini-mental state examination, Beck depression inventory, and state-trait anxiety inventory were performed, respectively. The participants were asked to complete the written consent form and were compensated for their participation. Finally, the auditoryverbal memory test was performed via Lenovo Z500 laptop which connected to a calibrated AC40 audiometer with TDH39 headphones.

The materials of the Persian version of the Bergen dichotic listening test were three sets of 36 pairs of syllables. Each syllable is made up of an stop consonant (/b, d, g, p, t, k/) plus vowel /a/. Each set was used for different experimental situations, including Non-forced attention (NF), Forced Right (FR), and Forced Left (FL). At the most comfortable level in NF situation, the subjects would hear a duplicated presentation of six syllables with a CV (consonant-vowel) pattern at a comfortable listening level, and they should repeat the best syllable heard after each presentation.

They should tell only one syllable. At the end of presentation, calculation of the percentage of correct answers and laterality of each ear in each situation was determined. The formula, LI = $(\mathrm{R}$ Ear $-\mathrm{L}$ Ear/R Ear $+\mathrm{L}$ Ear $) \times 100$, was used to determine the laterality of each ear in each experimental situation. In this formula, LI refers to laterality index, R Ear is the score of attention to the right, and L Ear is the score of attention to the left ear. If the LI were positive, it would indicate the right ear laterality, and if it were negative, it would mean the left ear laterality.

One-way ANOVA was done to measure any statistical difference between the three groups. The Student t-test was used to measure the effect of sex in each group, and the paired samples t-test was used to measure ear effect in each group. Statistical analysis was fulfilled with SPSS V. 25.

\section{Results}

Table 1 shows the characteristics of case and control groups. Information is expressed in Mean \pm SD.

Table 2 shows the results of one-way ANOVA for auditory attention in each ear separately by Non-Forced attention situation (NF). There was no significant difference between the three groups in scores of right ears and left ears separately.

Table 3 shows the results of the Student t-test for the sex effect in each group. There was no significant dif- 
Table 1. Demographic and clinical characteristic of study groups $(n=45)$

\begin{tabular}{|c|c|c|c|}
\hline \multirow{2}{*}{ Demographic Variables } & \multicolumn{2}{|c|}{ Subclinical Hypothyroidism } & \multirow{2}{*}{ Control } \\
\hline & $5<\mathrm{TSH} \leq 10$ & $10<\mathrm{TSH} \leq 15$ & \\
\hline Number & 15 & 15 & 15 \\
\hline Gender (male/female) & $6 / 9$ & $5 / 10$ & $6 / 9$ \\
\hline Age, y & $32.20 \pm 6.15$ & $32.66 \pm 4.46$ & $27.26 \pm 6.46$ \\
\hline PTA, min & $14.33 \pm 2.58$ & $13.33 \pm 3.08$ & $14 \pm 3.38$ \\
\hline $\mathrm{TSH}(\mu \mathrm{IU} / \mathrm{mL})$ & $6.87 \pm 0.94$ & $11.71 \pm 1.30$ & $1.82 \pm 1.19$ \\
\hline $\mathrm{T} 4$ ( $\mu \mathrm{g} / \mathrm{dL})$ & $7.52 \pm 2.09$ & $6.79 \pm 1.16$ & $7.85 \pm 1.86$ \\
\hline T3 (nmol/L) & $1.18 \pm 0.18$ & $1.30 \pm 0.35$ & $1.52 \pm 0.32$ \\
\hline Anti-TPO Ab (IU/mL) & $55.50 \pm 109.31$ & $16.61 \pm 0.58$ & - \\
\hline
\end{tabular}

Table 2. One-way ANOVA results for auditory attention between groups in each ear

\begin{tabular}{ccccccc}
\hline Ear & Group & Sum of Squares & df & Mean Square & F & Sig. \\
\hline Right ear & Between groups & 107.16 & 2 & 53.58 & 0.71 & 0.49 \\
Left ear & Between groups & 179.65 & 2 & 89.82 & 1.28 & 0.28 \\
\hline
\end{tabular}

ference in scores of right and left ears between men and women in three groups.

Table 4 shows the results of paired samples t-test for ear effect in each group. There was a significant differ- ence between scores of right and left ears in control and subclinical hypothyroid $5<\mathrm{TSH} \leq 10$ groups. But there was no significant difference between scores of right and left ears in subclinical hypothyroid $10<\mathrm{TSH} \leq 15$ group.

Table 3. The Independent samples t-test results comparing auditory attention in each group with sex- and ear-specific

\begin{tabular}{|c|c|c|c|c|c|c|}
\hline Group & Ear & Sex & Mean $\pm S D$ & df & $\mathbf{t}$ & $\mathbf{P}$ \\
\hline \multirow{2}{*}{ Control } & Right ear & $\begin{array}{l}\text { Female } \\
\text { Male }\end{array}$ & $\begin{array}{c}51.47 \pm 6.03 \\
57.77 \pm 11.08\end{array}$ & 13 & -1.43 & 0.30 \\
\hline & Left ear & $\begin{array}{l}\text { Female } \\
\text { Male }\end{array}$ & $\begin{array}{c}43.33 \pm 6.87 \\
37.21 \pm 10.62\end{array}$ & 13 & 1.36 & 0.53 \\
\hline \multirow{2}{*}{$\begin{array}{l}\text { Subclinical hypothy- } \\
\text { roid } 5<T S H \leq 10\end{array}$} & Right ear & $\begin{array}{l}\text { Female } \\
\text { Male }\end{array}$ & $\begin{array}{l}49.25 \pm 6.40 \\
47.77 \pm 10.68\end{array}$ & 13 & 0.33 & 0.33 \\
\hline & Left ear & $\begin{array}{l}\text { Female } \\
\text { Male }\end{array}$ & $\begin{array}{c}46.29 \pm 5.63 \\
47.21 \pm 12.18\end{array}$ & 13 & -0.20 & 0.12 \\
\hline \multirow{2}{*}{$\begin{array}{l}\text { Subclinical hypothy- } \\
\text { roid } 10<\mathrm{TSH} \leq 15\end{array}$} & Right ear & $\begin{array}{l}\text { Female } \\
\text { Male }\end{array}$ & $43.99 \pm 11.44$ & 13 & 2.72 & 0.12 \\
\hline & Left ear & $\begin{array}{l}\text { Female } \\
\text { Male }\end{array}$ & $\begin{array}{c}43.33 \pm 8.77 \\
41.99 \pm 15.54\end{array}$ & 13 & 0.72 & 0.41 \\
\hline
\end{tabular}


Table 4. Paired samples $t$ test results comparing auditory attention between groups in each ear

\begin{tabular}{ccccccc}
\hline Group & Number & Ear & Mean \pm SD & df & t & P \\
Control & 15 & Right & $53.99 \pm 8.65$ & 14 & 3.09 & 0.001 \\
$\begin{array}{c}\text { Subclinical hypothyroid } \\
5<\text { TSH } \leq 10\end{array}$ & 15 & Left & $40.88 \pm 8.77$ & & 0.48 & 0.000 \\
$\begin{array}{c}\text { Subclinical hypothyroid } \\
10<\text { TSH } \leq 15\end{array}$ & 15 & Left & $46.66 \pm 8.45$ & 14 & & 0.42 \\
\hline
\end{tabular}

Figure 1 shows the between-groups mean scores of auditory attention in the right ear and left ear. The mean scores of right ear in the control group is more than the mean scores of right ear in subclinical hypothyroid $5<\mathrm{TSH} \leq 10$ group, and the mean scores of right ear in the first subclinical hypothyroid $5<\mathrm{TSH} \leq 10$ group is more than the mean scores of right ear in the second subclinical hypothyroid $10<\mathrm{TSH} \leq 15$ group. But about left ear, there was not constant change in mean scores.

At first, the mean scores of left ear increased and then decreased. The laterality index was calculated in three groups. In the control group, $80 \%$ (12 people) had right ear advantage, $13.3 \%$ ( 2 people) had left ear advantage and $6.6 \%$ ( 1 person) had no ear advantage. In the first subclinical hypothyroid $(5<\mathrm{TSH} \leq 10)$ group, $66.66 \%$ (10 people) had right ear advantage, 20\% (3 people) had Left ear advantage, and $13.33 \%$ ( 2 people) had no ear advantages. In the second subclinical hypothyroid $(10<\mathrm{TSH} \leq 15)$ group, $73.33 \%$ (11 people) had right ear advantage, 20\% (3 people) had left ear advantage, and $6.66 \%$ ( 1 person) had no ear advantage.

\section{Discussion}

This study aimed to evaluate auditory divided attention in two subclinical hypothyroid $(5<\mathrm{TSH} \leq 10$, $10<\mathrm{TSH} \leq 15$ ) patient groups and a control group by the Persian version of the Bergen dichotic listening test. Findings indicated no significant difference among the three groups regarding the mean scores of right and left ear (Table 2). Gender did not affect-test results (Table 3 ). There were significant differences between scores of right and left ear between the first subclinical hypothyroid $(5<\mathrm{TSH} \leq 10)$ and the control groups, but there were no significant differences between scores of right and left ear in the second subclinical hypothyroid $(10<\mathrm{TSH} \leq 15)($ Table 4$)$.

Different studies showed different results about the effects of subclinical hypothyroidism on auditory atten-

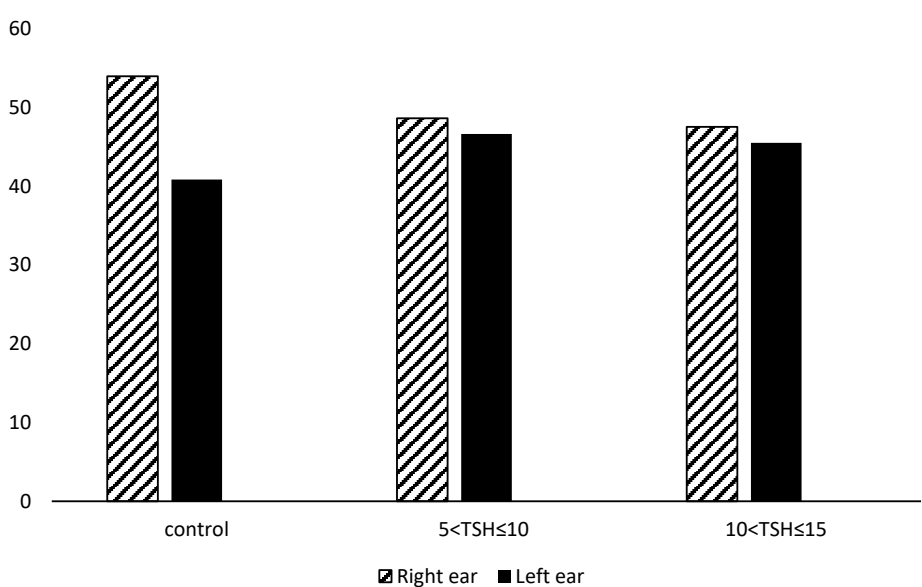

Figure 1. The mean scores of auditory attention with ear separation between groups 
tion $[18,19,25]$. For example, park et al. showed that auditory attention performance did not change in subclinical hypothyroid patients [24]. Jorde et al. found no difference between control and subclinical hypothyroid groups in auditory attention performance [25]. Baldini et al. showed that auditory attention performance did not change in subclinical hypothyroid patients. However, few studies yield opposite results [18]. Nystrom et al., in their research, proved that subclinical hypothyroidism had adverse effects on auditory attention [23]. Quijano et al. showed auditory attention performance reduction in patients with subclinical hypothyroidism [22].

Different results in previous studies about the effect of subclinical hypothyroidism on auditory attention could be explained by hormone level disturbances, cognitive involvements, and anxiety. It was demonstrated that the lower levels of TSH hormone might suppress the effects of subclinical hypothyroidism on auditory attention because of a direct relationship between TSH hormone level and severity of the disorder [30].

Another reason is the effect of aging because older patients usually have some cognitive dysfunctions such as reduction of memory and attention performance and depression; these confounding factors can have adverse effects on the test results. So that changes of auditory attention could be due to the effects of aging and not the direct effect of subclinical hypothyroidism. Another reason is ignoring the neuropsychological factors such as anxiety before doing tests. Anxiety is one of the factors that may have adverse effects on the test results. Some studies disregard this factor, do the tests, and ignore the stress of their subjects [25].

In the present study, the Persian version of the Bergen dichotic listening test was used on patients with subclinical hypothyroid. Therefore, the method of presenting stimuli and calculating scores was different from other auditory attention tests. For this reason, we could not compare the results of this test with the results of other studies. As Bergen dichotic test is one of the tasks that require a lot of processing and mental demanding, the subclinical hypothyroidism in the present study could not sufficiently influence the processing centers that advocate for auditory divided attention [31].

One reason may be the less sensitivity of these areas to subclinical hypothyroidism. According to much evidence, in changing levels of thyroid hormones, different areas of the brain, including cognitive levels with different sensitivities, exhibit different functions [32, 33]. Probably the prefrontal cortex for processing of divided attention is not sensitive under these conditions [34]. These hypotheses, however, are beyond the scope of the current study; hence, further studies are needed to determine the reliability of the effect of subclinical hypothyroidism on auditory attention.

In the current study, there were significant differences between scores of right ear and left ear in the control and subclinical hypothyroid $(5<\mathrm{TSH} \leq 10)$ groups in the way that scores of the right ear were higher than scores of left ears. Jafari et al., in two studies, assessed scores of right and left ear in auditory attention utilizing Bergen dichotic test in healthy adults. They found that scores of the right ear were more than scores of left ear $[13,35]$.

The results of these two studies were consistent with the control and the subclinical hypothyroidism $(5<\mathrm{TSH} \leq 10)$ groups of the present study. Right ear advantage is a stable index that represents anatomical differences in right and left sides of the central auditory nervous system [35, 36]. It means that contralateral neural tracts compared with ipsilateral neural tracts are wider. Moreover, left hemisphere compared with right hemisphere has been specialized for language inputs. Therefore, speech stimuli presented to right ear are processed more faster than left ear [35].

In the subclinical hypothyroid $(10<\mathrm{TSH} \leq 15)$ group, although there was no significant difference between scores of right and left ears, the scores of the right ear were more than left ear. It seems that the non-significant difference was due to the higher standard deviation in subclinical hypothyroid $(10<\mathrm{TSH} \leq 15)$ group, compared with the two other groups. Because the obtained data were scattered, the possibility of a significant difference would be low. On the other hand, laterality index in the subclinical hypothyroid $(10<\mathrm{TSH} \leq 15)$ group is the same as two other groups, and most of the patients in this group had right ear advantage. Therefore, it seems unlikely that subclinical hypothyroidism affects right ear advantage.

There was no significant difference between men and women in three groups regarding the scores of the right and left ear. Jafari et al., in their study, evaluated the effect of gender on the auditory attention by the Bergen dichotic test in 75 healthy adults. They found that gender did not affect auditory attention [13].

These results were similar to the results of the analysis of data from the Bergen dichotic test database, which was conducted on nearly 1000 people [37]. Sommer et al. assessed the effect of gender on auditory attention. 
They reported no significant difference between men and women in auditory attention [38]. Hiscook et al. evaluated 477 healthy right-handed adults in five successive tests using dichotic language stimuli in which gender did not affect dichotic test results [39]. These studies were similar in their outcomes with the results of the present study.

The present study had a few limitations. First, our sample size was small due to difficulty in access to the appropriate participants, and second, we did not have enough time for conducting longitudinal study. Future studies are recommended to consider larger sample size and long-term follow-up to find out subtle changes in the subclinical hypothyroidism patients.

\section{Conclusion}

In the present study, subclinical hypothyroidism had no adverse effect on auditory divided attention. Also, subclinical hypothyroidism had no significant impact on right ear advantage in both case groups. Finally, gender did not affect dichotic test results.

\section{Ethical Considerations}

\section{Compliance with ethical guidelines}

The current study protocol was approved by the Ethics Committee of Tehran University of Medical Sciences with the Code: IR.TUMS.FNM.REC.1397.128.

\section{Funding}

The present paper was extracted from the MSc. thesis of the first author, Fatemeh Khorasani, in Department of Audiology, School of Rehabilitation, Tehran University of Medical Sciences, Tehran.

\section{Authors contributions}

Original manuscript draft: Fatemeh Khorasani; Designing and developing; The protocol: Nematollah Rouhbakhsh, Fatemeh Khorasani; Editing the manuscript: Nematollah Rouhbakhsh, Ahmad Geshani, Mohammad Reza Mohajeri Tehrani; Statistical analysis: Mostafa Qorbani.

\section{Conflict of interest}

The authors declared no conflict of interest.

\section{Acknowledgements}

The authors acknowledge the financial support of Tehran University of Medical Sciences. More importantly, conducting this project is owed to Endocrinology and Metabolism Research Institute, Tehran University of Medical Sciences, for their helping in recruiting the participants.

\section{References}

[1] Aminorroaya A, Meamar R, Amini M, Feizi A, Tabatabae A, Imani EF. Incidence of thyroid dysfunction in an Iranian adult population: The predictor role of thyroid autoantibodies: Results from a prospective population-based cohort study. European Journal of Medical Research. 2017; 22(1):21. [DOI:10.1186/s40001-017-0260-2] [PMID] [PMCID]

[2] Surks MI, Ortiz E, Daniels GH, Sawin CT, Col NF, Cobin $\mathrm{RH}$, et al. Subclinical thyroid disease: Scientific review and guidelines for diagnosis and management. The Journal of the American Medical Association. 2004; 291(2):228-38. [DOI:10.1001/jama.291.2.228] [PMID]

[3] McDermott MT, Ridgway EC. Subclinical hypothyroidism is mild thyroid failure and should be treated. The Journal of Clinical Endocrinology \& Metabolism. 2001; 86(10):4585-90. [DOI:10.1210/jcem.86.10.7959] [PMID]

[4] Owen PJ, Lazarus JH. Subclinical hypothyroidism: The case for treatment. Trends in Endocrinology \& Metabolism. 2003; 14(6):257-61. [DOI:10.1016/S1043-2760(03)00108-5]

[5] Almeida C, Vaisman M, Costa AJL, Reis FA, Reuters V, Teixeira $P$, et al. Are neuropsychological changes relevant in subclinical hypothyroidism? Arquivos Brasileiros de Endocrinologia \& Metabologia. 2007; 51(4):606-11. [DOI:10.1590/ S0004-27302007000400016] [PMID]

[6] Sangün Ö, Demirci S, Dündar N, Pirgon Ö, Koca T, Doğan $\mathrm{M}$, et al. The effects of six-month L-thyroxine treatment on cognitive functions and event-related brain potentials in children with subclinical hypothyroidism. Journal of Clinical Research in Pediatric Endocrinology. 2015; 7(2):102 [DOI:10.4274/jcrpe.1684] [PMID] [PMCID]

[7] Paladugu S, Hanmayyagari BR, Kudugunti N, Reddy R Sahay R, Ramesh J. Improvement in subclinical cognitive dysfunction with thyroxine therapy in hypothyroidism: A study from tertiary care center. Indian Journal of Endocrinology and Metabolism. 2015; 19(6):829-33. [DOI:10.4103/22308210.167547] [PMID] [PMCID]

[8] Akintola AA, Jansen S, van Bodegom D, van der Grond J, Westendorp R, de Craen A, et al. Subclinical hypothyroidism and cognitive function in people over 60 years: A systematic review and meta-analysis. Frontiers in Aging Neuroscience. 2015; 7:150. [DOI:10.3389/fnagi.2015.00150] [PMID] [PMCID]

[9] Medwetsky L, Katz J, Burkhard R, Hood L. Mechanisms underlying central auditory processing. Handbook of Clinical Audiology. 2009; 6:712-25

[10] Jafari Z, Aghamollaei M, Toufan R, AsadMalayeri S, Esmaili M, Rahimzadeh S. Effects of handedness and gender on 
auditory attention in Bergen dichotic listening. Advances in Cognitive Science. 2012; 14(1):1-10.

[11] Aylward GP, Brager P, Harper DC. Relations between visual and auditory continuous performance tests in a clinical population: A descriptive study. Developmental Neuropsychology. 2002; 21(3):285-303. [DOI:10.1207/ S15326942DN2103_5] [PMID]

[12] Soltanparast S, Jafari Z, Sameni SJ, Salehi M. A Persian version of the sustained auditory attention capacity test and its results in normal children. Bimonthly Audiology-Tehran University of Medical Sciences. 2013; 22(1):85-94.

[13] Jafari Z, Aghamollaei M, Toufan R, Malayeri S, Esmaili M, Rahimzadeh S. Effects of hadedness and gender on auditory attention in Bergen dichotic listening. Advances in Cognitive Science. 2012; 14(1):1-10.

[14] Boustanzar R, Rezayi S. Developing intervention program focused and divided attention and investigating its effectiveness on working memory iq in children with specific learning disorder. Journal of Learning Disabilities. 2017; 7(1):7-25.

[15] Encyclopaedia Britannica. Leaf-nosed bat. Encyclopædia Britannica Online; 2009.

[16] Hugdahl K. Dichotic listening in the study of auditory later- ality. In: Davidson, RJ, Hugdahl K, editors. The Asymmetrical Brain. Cambridge. MIT Press; 2003.

[17] Holender D. Semantic activation without conscious identification in dichotic listening, parafoveal vision, and visual masking: A survey and appraisal. Behavioral and Brain Sciences. 1986; 9(1):1-23. [DOI:10.1017/S0140525X00021269]

[18] Baldini M, Colasanti A, Orsatti A, Airaghi L, Mauri MC, Cappellini MD. Neuropsychological functions and metabolic aspects in subclinical hypothyroidism: The effects of L-thyroxine. Progress in Neuro-Psychopharmacology and Biological Psychiatry. 2009; 33(5):854-9. [DOI:10.1016/j.pnpbp.2009.04.009] [PMID]

[19] Gussekloo J, van Exel E, de Craen AJ, Meinders AE, Frölich M, Westendorp RG. Thyroid status, disability and cognitive function, and survival in old age. The Journal of the American Medical Association. 2004; 292(21):2591-9. [DOI:10.1001/ jama.292.21.2591] [PMID]

[20] Parle J, Roberts L, Wilson S, Pattison H, Roalfe A, Haque M, et al. A randomized controlled trial of the effect of thyroxine replacement on cognitive function in community-living elderly subjects with subclinical hypothyroidism: The Birmingham elderly thyroid study. The Journal of Clinical Endocrinology \& Metabolism. 2010; 95(8):3623-32. [DOI:10.1210/ jc.2009-2571] [PMID]

[21] de Jongh RT, Lips P, van Schoor NM, Rijs KJ, Deeg DJ, Comijs HC, et al. Endogenous subclinical thyroid disorders, physical and cognitive function, depression, and mortality in older individuals. European Journal of Endocrinology. 2011; 165(4):545-54. [DOI:10.1530/EJE-11-0430] [PMID]

[22] Delgado C, Martínez SE, Vázquez C. Cognitive deficiency in mild hypothyroidism. Neurologia. 2000; 15(5):193-8.

[23] Nyström E, Caidahl K, Fager G, Wikkelsö C, Lundberg PA, Lindstedt G. A double-blind cross-over 12-month study of L-thyroxine treatment of women with 'subclinical' hypothyroidism. Clinical Endocrinology. 1988; 29(1):63-76. [DOI:10.1111/j.1365-2265.1988.tb00250.x] [PMID]
[24] Park YJ, Lee EJ, Lee YJ, Choi SH, Park JH, Lee SB, et al. Subclinical hypothyroidism $(\mathrm{SCH})$ is not associated with metabolic derangement, cognitive impairment, depression or poor Quality of Life (QoL) in elderly subjects. Archives of Gerontology and Geriatrics. 2010; 50(3):e68-73. [DOI:10.1016/j.archger.2009.05.015] [PMID]

[25] Jorde R, Waterloo K, Storhaug H, Nyrnes A, Sundsfjord J, Jenssen TG. Neuropsychological function and symptoms in subjects with subclinical hypothyroidism and the effect of thyroxine treatment. The Journal of Clinical Endocrinology \& Metabolism. 2006; 91(1):145-53. [DOI:10.1210/jc.2005-1775] [PMID]

[26] Davis JD, Stern RA, Flashman LA. Cognitive and neuropsychiatric aspects of subclinical hypothyroidism: Significance in the elderly. Current Psychiatry Reports. 2003; 5(5):384-90. [DOI:10.1007/s11920-003-0073-6] [PMID]

[27] Roberts LM, Pattison H, Roalfe A, Franklyn J, Wilson $\mathrm{S}$, Hobbs FR, et al. Is subclinical thyroid dysfunction in the elderly associated with depression or cognitive dysfunction? Annals of Internal Medicine. 2006; 145(8):573-81 [DOI:10.7326/0003-4819-145-8-200610170-00006] [PMID]

[28] Samuels MH. Cognitive function in subclinical hypothyroidism. Oxford. Oxford University Press; 2010. [DOI:10.1210/jc.2010-1242] [PMID]

[29] Hugdahl K, Law I, Kyllingsbæk S, Brønnick K, Gade A, Paulson OB. Effects of attention on dichotic listening: An 15O-PET study. Human Brain Mapping. 2000; 10(2):87-97. [DOI:10.1002/(SICI)1097-0193(200006)10:23.0.CO;2-V]

[30] Zulewski H, Muiller B, Exer P, Miserez AR, Staub JJ. Estimation of tissue hypothyroidism by a new clinical score: Evaluation of patients with various grades of hypothyroidism and controls. The Journal of Clinical Endocrinology \& Metabolism. 1997; 82(3):771-6. [DOI:10.1210/jc.82.3.771] [PMID]

[31] Westerhausen R, Hugdahl K. The corpus callosum in dichotic listening studies of hemispheric asymmetry: A review of clinical and experimental evidence. Neuroscience \& Biobehavioral Reviews. 2008; 32(5):1044-54. [DOI:10.1016/j.neubiorev.2008.04.005] [PMID]

[32] Kimura N, Kumamoto T, Masuda H, Hanaoka T, Hazama Y, Okazaki T, et al. Relationship between thyroid hormone levels and regional cerebral blood flow in Alzheimer disease. Alzheimer Disease \& Associated Disorders. 2011; 25(2):138-43. [DOI:10.1097/WAD.0b013e3181f9aff2] [PMID]

[33] Krausz Y, Freedman N, Lester H, Newman J, Barkai G, Bocher $\mathrm{M}$, et al. Regional cerebral blood flow in patients with mild hypothyroidism. Journal of Nuclear Medicine. 2004 45(10):1712-5.

[34] Don M, Kwong B, Katz J. Handbook of clinical audiology. Philadelphia: Lippincott Williams \& Wilkins; 2002.

[35] Jafari Z, Toufan R, Aghamollaei M, Malayeri S, Rahimzadeh S, Esmaili M. Constructing Persian version of the Bergen dichotic listening test and its preliminary results in normal adults. Bimonthly Audiology-Tehran University of Medical Sciences. 2013; 22(3):31-41.

[36] Andersson M, Llera JE, Rimol LM, Hugdahl K. Using dichotic listening to study bottom-up and top-down processing in children and adults. Child Neuropsychology. 2008; 14(5):470-9. [DOI:10.1080/09297040701756925] [PMID] 
[37] Hugdahl K. The Asymmetrical Brain. MA: MIT Press; 2003.

[38] Sommer IE, Aleman A, Somers M, Boks MP, Kahn RS. Sex differences in handedness, asymmetry of the planum temporale and functional language lateralization. Brain Research. 2008; 1206:76-88. [DOI:10.1016/j.brainres.2008.01.003] [PMID]

[39] Hiscock M, Inch R, Jacek C, Hiscock-Kalil C, Kalil KM. Is there a sex difference in human laterality? I. An exhaustive survey of auditory laterality studies from six neuropsychology journals. Journal of Clinical and Experimental Neuropsychology. 1994; 16(3):423-35. [DOI:10.1080/01688639408402653] [PMID] 
This Page Intentionally Left Blank 